\title{
Technical Note: Measuring condensation sink and ion sink of atmospheric aerosols with the electrical low pressure impactor (ELPI)
}

\author{
H. Kuuluvainen ${ }^{1}$, J. Kannosto ${ }^{1}$, A. Virtanen ${ }^{1}$, J. M. Mäkelä ${ }^{1}$, M. Kulmala ${ }^{2}$, P. Aalto ${ }^{2}$, and J. Keskinen ${ }^{1}$ \\ ${ }^{1}$ Aerosol Physics Laboratory, Department of Physics, Tampere University of Technology, P.O. Box 692, \\ 33101 Tampere, Finland \\ ${ }^{2}$ Department of Physical Sciences, Division of Atmospheric Sciences, University of Helsinki, P.O. Box 64, \\ 00014 University of Helsinki, Finland
}

Received: 12 May 2009 - Published in Atmos. Chem. Phys. Discuss.: 27 July 2009

Revised: 14 January 2010 - Accepted: 20 January 2010 - Published: 5 February 2010

\begin{abstract}
We investigate the suitability of ELPI for condensation sink and ion sink measurements. The aim is to find the simple calibration factors by which the measured ELPI current can be converted to condensation or ion sinks. The calibration is based on DMPS and ELPI measurements within the period 15-25 May 2005 at a boreal forest site in Southern Finland. The values of condensation sink and ion sink were calculated from the DMPS size distributions using their theoretical definitions. After that the values were compared to theoretical and measured ELPI current, and calibration factors were specified. For condensation sink the calibration factor was found to be 7.27E-06 s s. $^{-1} \mathrm{fA}^{-1}$ and for ion sink $8.55 \mathrm{E}-06 \mathrm{~s}^{-1} \mathrm{fA}^{-1}$. Simply by multiplying the total current of the outdoor ELPI by these factors, the values of condensation sink and ion sink can be measured.
\end{abstract}

\section{Introduction}

Aerosol particles are omnipresent in the Earth's atmosphere and involved in many atmospheric prosecces affecting the global climate system. Direct effects, including light scattering and absorption, are physically rather simple and wellknown phenomena, as against indirect effects related to cloud formation are more complicated (Lohmann and Feichter, 2005; Haywood and Shine, 1995). Uncertainty in these indirect effects has lately motivated us to investigate especially some basic phenomena of atmospheric aerosols: the formation of new particles and their subsequent growth process (Kulmala and Kerminen, 2008; Kulmala et al., 2004).
The growth process of atmospheric aerosol particles is mainly condensational in the presence of condensable species, e.g. water and sulphuric acid with a low vapour pressure. In this respect, the concept of condensation sink (Pirjola et al., 1999; Kulmala et al., 2001) is useful. In addition to the condensable species, there are always some ions present in the air. When ions attach onto the particles, the concept of ion sink becomes relevant. Because in these processes aerosol particles interact with molecules or ions through their surface, condensation sink and ion sink are also related to surface metrics called Fuchs surface (Pandis et al., 1991) and active surface (Siegmann and Siegmann, 2000).

The surface-related quantities can be calculated from size distribution and concentration measured with (e.g.) Differential Mobility Particle Sizer (DMPS) or Scanning Mobility Particle Sizer (SMPS). However, they can also be measured more directly with intruments that mimic the size dependence of these quantities (Shin et al., 2007; Bukowiecki et al., 2002; Woo et al., 2001; Keskinen et al., 1991; Gäggeler et al., 1989). One of the most promising instruments for the real-time measurements of these quantities is a diffusion charger. What happens in a diffusion charger when ions attach onto the particles is closely related to natural condensation or ion attachment in the atmosphere. Accordingly, it has been shown that the output signal of the diffusion charger is almost directly proportional to many surface related quantities (Fissan et al., 2006; Ntziachristos et al., 2004). Recently, Ntziachristos et al. (2007) applied the Nanoparticle Surface Area Monitor (NSAM, TSI, Inc.) for the measurement of particle surface concentrations of urban and traffic aerosols. 
In this study we focus on the electrical low pressure impactor (ELPI), developed by Keskinen et al. (1992). In the ELPI, the sample flow passes through a diffusion charger into a cascade impactor. Each impactor stage is connected to a sensitive current-to-voltage amplifier (electrometer). In normal operation, each electrometer signal is treated separately to calculate size distribution. However, the instrument can also be treated as a diffusion charger simply by summing up all the electrometer signals. We first treat the theoretical instrument to condensation sink and ion sink. We then check this with experimental data and calculate calibration factors for both condensation sink and ion sink measurement.

\section{Attachment rates}

If aerosol particles are surrounded by atoms, molecules or ions that attach to the particles, the concentration of the present species $n$ obeys the first order differential equation

$$
\frac{\mathrm{d} n}{\mathrm{~d} t}=-X n
$$

where $X$ is the attachment rate of the species onto the particles. For a polydispersed aerosol the attachment rate is obtained by integrating a particle size dependent attachment rate factor $A_{X}\left(d_{p}\right)$ over the aerosol size distribution $\mathcal{N}\left(d_{p}\right)$ :

$X=\int A_{X}\left(d_{p}\right) \mathcal{N}\left(d_{p}\right) \mathrm{d} d_{p}$.

These expressions were originally used for the attachment of airborne radioactive species onto aerosol particles (e.g. Porstendörfer and Mercer, 1978) but they are quite generic. We apply them to condensing species (marking $X=\mathrm{CS}$ and $A_{X}=A_{\mathrm{CS}}$ ) and to attaching ions (marking $X=\mathrm{IonS}$ and $A_{X}=A_{\text {Ions }) \text {. }}$

\subsection{Condensation sink}

For condensing atoms and molecules, we name the rate quantity of equation (1) as condensation sink (CS) and the corresponding attachment rate factor as condensation sink factor $A_{\mathrm{CS}}\left(d_{p}\right)$. The latter is defined as:

$A_{\mathrm{CS}}\left(d_{p}\right)=2 \pi d_{p} D_{m} \beta\left(d_{p}\right)$,

where $d_{p}$ is the particle diameter, $D_{m}$ the diffusion coefficent of the gas molecules and $\beta$ the Fuchs correction factor. As a correction factor we use the Fuchs and Sutugin (1971) formula in the form of

$\beta=\frac{1+K n}{1+\left(\frac{4}{3 \alpha}+0.377\right) K n+\frac{4}{3 \alpha} K n^{2}}$,

where $K n$ is the relation of the particle diameter and the mean free path of the gas $\lambda_{m}$, called Knudsen number. The particle size dependence of the condensation sink factor is shown in Fig. 1.

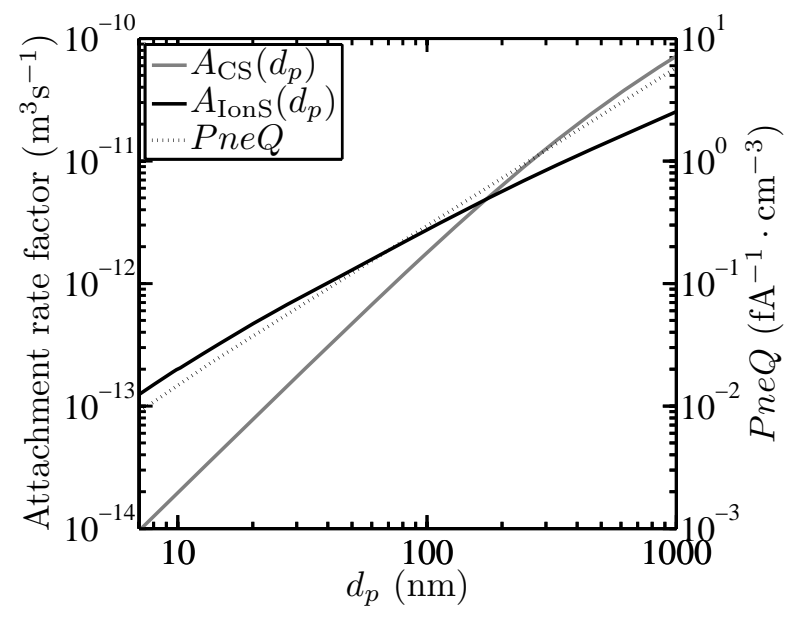

Fig. 1. The particle size dependence of the attachment rate factors for condensation sink $\left(A_{\mathrm{CS}}\left(d_{p}\right)\right)$ and ion sink $\left(A_{\mathrm{IonS}}\left(d_{p}\right)\right)$. The number sensitivity function of the outdoor ELPI (Pne $Q)$ is shown on secondary vertical axis.

According to the definition, the condensation sink of the aerosol depends on the properties of the molecules or the atoms, i.e. the diffusion coefficient and the mean free path. The diffusion coefficient of vapour molecules in the air is calcuated as (Poling et al., 2000)

$$
D_{\text {vap }}=0.00143 \cdot T^{1.75} \frac{\sqrt{M_{\text {air }}^{-1}+M_{\text {vap }}^{-1}}}{P\left(D_{x, \text { air }}^{1 / 3}+D_{x, \text { vap }}^{1 / 3}\right)^{2}},
$$

where $P$ is the air pressure, $M$ the molar mass and $D_{x}$ the diffusion volume, which is calculated from the table of atomic diffusion volumes gathered by Poling et al. (2000). In this paper we use the properties of sulfuric acid because it has been identified as a key component in atmospheric aerosol formation and growth (Riipinen et al., 2007). The values are found to be $D_{x \text {,air }}=19.7$ and $D_{x \text {,vap }}=51.66$ for sulfuric acid molecules. Thus we get the diffusion coefficient of sulfuric acid. The relation between the diffusion coefficient and the mean free path is known to be $\lambda_{m}=3 \bar{c}_{m} / D_{m}$, where $\bar{c}_{m}$ is the mean thermal velocity of the molecules. Due to the temperature-dependent molecule properties, we have now the condensation sink dependent on temperature. The molecule properties are also dependent on the air pressure, but in this paper it is kept invariant.

\subsection{Ion sink}

For airborne ions, we name the rate quantity of equation (1) as ion sink (IonS) and the corresponding attachment rate factor as ions sink factor $A_{\text {IonS }}\left(d_{p}\right)$. The ion sink factor is defined as:

$A_{\text {IonS }}\left(d_{p}\right)=\int \eta\left(d_{p}, p\right) \Psi\left(d_{p}, p\right) \mathrm{d} p$, 
where $p$ is the number of elementary units of charge and $\eta$ is the combination coefficient introduced by Fuchs (1963). The integral is taken over the particle charge distribution $\Psi$, as which we use a Fuchs equilibrium charge distribution calculated with the combination coefficients (Fuchs, 1963). We adopt the notation used by Adachi et al. (1985) for the combination coefficient

$$
\eta=\frac{\pi \bar{c}_{i} \xi \delta^{2} \exp \left(\frac{-\phi(\delta)}{k_{B} T}\right)}{1+\exp \left(\frac{-\phi(\delta)}{k_{B} T}\right) \frac{\bar{c}_{i} \xi \delta^{2}}{4 D_{i} a} \int_{0}^{a / \delta} \exp \left(\frac{\phi(a / x)}{k_{B} T}\right) \mathrm{d} x},
$$

where $a=d_{p} / 2, x=a / r$ and

$$
\begin{aligned}
\delta=\frac{a^{3}}{\lambda_{i}^{2}}\left(\frac{1}{5}\left(1-\frac{\lambda_{i}}{a}\right)^{5}-\right. & \frac{1}{3}\left(1+\frac{\lambda_{i}^{2}}{a^{2}}\right)\left(1+\frac{\lambda_{i}}{a}\right)^{3} \\
& \left.+\frac{2}{5}\left(1+\frac{\lambda_{i}^{2}}{a^{2}}\right)^{5 / 2}\right), \\
\phi(r)= & \frac{p e^{2}}{4 \pi \varepsilon_{0} r}-\frac{\varepsilon_{r}-1}{\varepsilon_{0}-1} \frac{e^{2}}{8 \pi \varepsilon_{0}} \frac{a^{3}}{r^{2}\left(r^{2}-a^{2}\right)},
\end{aligned}
$$

where $r$ is the distance between ion and particle centre, $e$ the elementary charge, $\varepsilon_{0}$ the dielectric constant, $\varepsilon_{r}$ the specific dielectric constant, $\lambda_{i}$ the mean free path of ions and $\xi$ the striking probability. The size dependence of ion sink factor is shown in Fig. 1. The charge distribution is taken account as if there were a monodisperse distribution corresponding to each particle size.

There are several ways to calculate the ion properties introduced above. We use the following equations (Hoppel and Frick, 1986):

$$
\begin{aligned}
D_{i} & =k_{B} T Z_{i} / e \\
\bar{c}_{i} & =\sqrt{\frac{8 k_{B} T}{\pi\left(M_{i} / N_{A}\right)}} \\
\lambda_{i} & =\frac{4 Z_{i}}{3 e} \sqrt{\frac{8 k_{B} T M_{\text {air }}^{2}}{\pi\left(M_{i}+M_{\text {air }}\right) N_{A}}},
\end{aligned}
$$

where $D_{i}$ is the diffusion coefficient, $Z_{i}$ the electrical mobility, $k_{B}$ the Boltzmann coefficient, $\bar{c}_{i}$ the mean thermal velocity, $M$ the molar mass, $N_{A}$ the Avogadro number and $\lambda_{i}$ the mean free path. The electrical mobility of ions is dependent on temperature and pressure. Commonly used notation for the dependence is (Eiceman and Karpas, 2005)

$Z_{i}=Z_{0} \frac{P}{P_{0}} \frac{T_{0}}{T}$

In this paper only the temperature dependence is taken into account and the pressure is kept invariant.

The ion properties are known to have a distribution of different mobility values, depending on the chemical composition of air, including tracer amounts of various vapours (e.g. Eisele and Tanner, 1990). Ion sink is typically employed in studying the balance between small ions and fine aerosol particles and in the calculation of ion production rate in the atmosphere (e.g. Hõrrak et al., 2008). The ion properties relevant in this context are those of the aged ambient air ions. Like Hõrrak et al. (2008), we approximate the ion distribution by monodispersed ion characteristics. Following Adachi et al. (1985) and Vohra et al. (1969) we choose the mean mobility for positive ions to be $1.40 \mathrm{~cm}^{2} / \mathrm{Vs}$, and mass 109 amu.

\section{The attachment rates compared to ELPI current}

Based on the idea and the definition of ion sink, it can be expected that diffusion charging process, where ions produced by corona discharge attach on aerosol particles, is somehow proportional to ion sink. Using so-called active surface metric, which is directly proportional to ion sink, Ntziachristos et al. (2004) showed that this quantity correlates with the current signal of the diffusion charger. They also showed that there is a small difference between the active and the socalled Fuchs surface metric, the latter of which is directly proportional to condensation sink.

\subsection{ELPI response function}

The electrical low pressure impactor (ELPI) is an instrument that, by calculating the total current of all impactor stages, provides a real-time current signal of the particles charged with a diffusion charger. Using the notation of Keskinen et al. (1991) the total current, as an outputsignal of ELPI, can be expressed as

$I=\int S_{N}\left(d_{p}\right) \mathcal{N}\left(d_{p}\right) \mathrm{d} d_{p}$

where $S_{N}\left(d_{p}\right)$ is defined as a number sensitivity function of the instrument. According to Marjamäki et al. (2000) the number sensitivity function of ELPI is

$S_{N}\left(d_{p}\right)=\operatorname{Pn}\left(d_{p}\right) e Q$

where $P$ is the penetration through the charger, $n$ is the number of single charges per particle and $Q$ is the flowrate through the charger. In our measurements we used an outdoor ELPI, which had a flowrate $Q=28.911 / \mathrm{s}$. The manufacturer (Dekati Ltd., 2003) gives the number sensitivity function of the outdoor ELPI as:

Pne $Q=\left\{\begin{array}{l}3.0924 \cdot \frac{Q}{Q_{0}} \cdot d_{p}^{1.3915}, d_{p} \leq 0.0135 \mu \mathrm{m} \\ 2.0000 \cdot \frac{Q}{Q_{0}} \cdot d_{p}^{1.2902}, d_{p}>0.0135 \mu \mathrm{m}\end{array}\right.$,

where $Q_{0}=10 \mathrm{l} / \mathrm{s}$ and the unit of the quantity $P n e Q$ is $1 /\left(\mathrm{fA} \cdot \mathrm{cm}^{3}\right)$. The number sensitivity function compared to the attachment rate factors is shown in Fig. 1. 


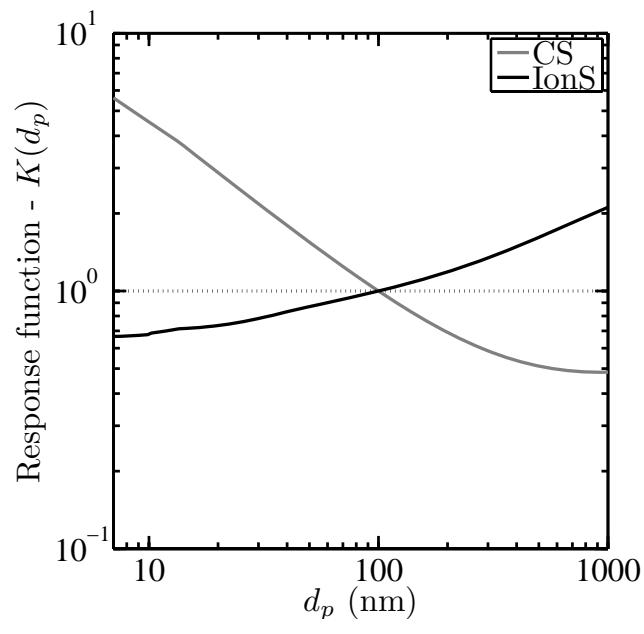

Fig. 2. Response functions of the ELPI total current signal for the condensation sink (CS), and for the ion sink (IonS). The functions are normalized at $100 \mathrm{~nm}$.

If the intention is to determine a quantity $A\left(d_{p}\right)$, the instrument is said to be ideal if $S_{N}\left(d_{p}\right)=K A\left(d_{p}\right)$ and $K$ is a constant. In the non-ideal case the sensitivity function is not directly proportional to $A\left(d_{p}\right)$ and we can define a size dependent quantity

$K\left(d_{p}\right)=\frac{S_{N}\left(d_{p}\right)}{A\left(d_{p}\right)}$,

which is called the response function of the instrument specified by $A\left(d_{p}\right)$. Specifically, we are interested in the response functions specified by the factors $A_{\mathrm{CS}}$ and $A_{\text {IonS }}$, defined in equations (3) and (6), respectively (Fig. 2). The only quantity, that actually behaves ideally, is the number sensitivity function itself. However, as could be seen in the Fig. 2, the response function specified by ion sink differs only slightly from the ideal behaviour. The response is near-ideal also in the case of condensation sink.

\section{Measurements}

The field measurements were carried out at the SMEAR II station (Hari and Kulmala, 2005) in Hyytiälä, Southern Finland, between 15 and 25 May 2005. The field station is located in a boreal forest and it represents a typical background area of Finland. Concentration and consistence of the aerosol are highly dependent on wind direction and air mass trajectories.

The period of May was chosen because there were a number of changes in the size distrubution of particles as well as in temperature, and these ten days represent well the roundyear average. Examples of the number size distributions and the average distribution are shown in Fig. 3. All the measured distributions during the period are plotted as a function of time in Fig. 7a.

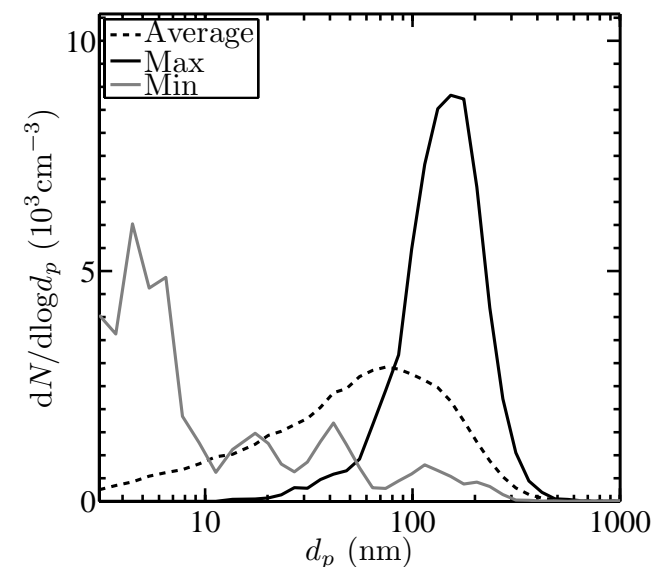

Fig. 3. Examples of the number size distributions measured with DMPS at Hyytiälä in May 2005. Min means the distribution with the lowest GMD and Max the distribution with the greatest GMD. Average is the mean size distribution during this time period.

Particle size distributions were measured with DMPS, including two Vienna type DMAs with $10.9 \mathrm{~cm}$ and $28 \mathrm{~cm}$ tube lengths, CPC 3025 and CPC 3010 (Mäkelä et al., 1997). In addition, there was an outdoor ELPI. The time resolutions of ELPI and DMPS were one and ten minutes, respectively, but the ELPI data was averaged over ten minutes to correspond the DMPS data. The ELPI measures particles approximately in the size range $7 \mathrm{~nm}-6 \mu \mathrm{m}$ while the DMPS size range is about $3 \mathrm{~nm}-500 \mathrm{~nm}$. Along with these aerosol particle measurements outdoor air temperature was measured continuously during the period.

All the measuring instruments in Hyytiälä were located in a cabin with a relatively stable room temperature and the outdoor air sample was led to them. Before the ELPI the sample was dried so that it would not humidify the instrument in continuous measurements. In the case of DMPS the sheath air used in DMA was dry and at room temperature, which practically makes the measured sample to be dry as well. This arrangement allows us to ignore in the calibration the effect of temperature and air humidity variation on the measuring instruments. On the other hand it prevents us to prove the operation of ELPI in varying measuring conditions and study the effect of air humidity on sink processes. However, to our knowledge, in measuring the sink processes there is no reference instrument, which is proved to work properly in varying measuring conditions.

In addition to the field campaign, we made laboratory measurements using polydispersed $\mathrm{NaCl}$ aerosols. In the measurements we used an outdoor ELPI and corresponding to DMPS there was SMPS with a size range $9.8 \mathrm{~nm}-445 \mathrm{~nm}$ (Wang and Flagan, 1990). Particle size distributions with GMD varying from $22 \mathrm{~nm}$ to $140 \mathrm{~nm}$ and with concentrations approximately from $1 \mathrm{E} 3 \mathrm{~cm}^{-3}$ to $1 \mathrm{E} 6 \mathrm{~cm}^{-3}$ were generated and they were measured with both the instruments. 

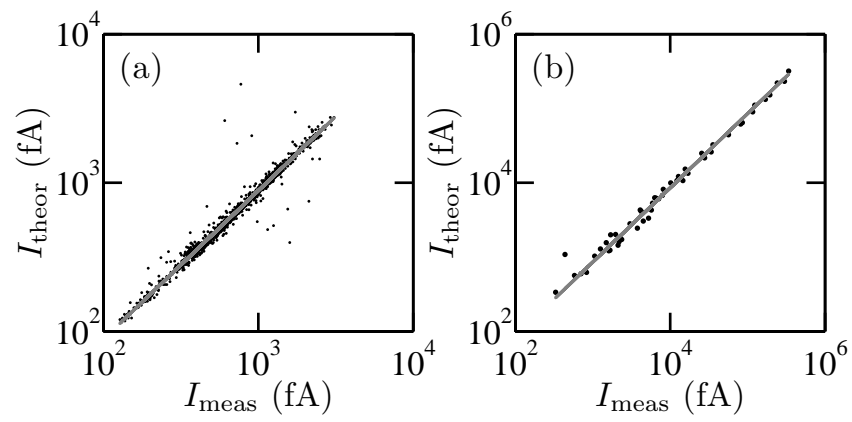

Fig. 4. Theoretical ELPI current as a function of measured ELPI current. In the field measurements (a) the slope of the fitting is 0.885 and in the laboratory measurements (b) it is 0.854 .

\section{Calibration}

In the calibration values of condensation sink and ion sink were at first calculated using the measured DMPS size distributions, the Eq. (3) and (6), the properties of sulfuric acid molecules and positive ions represented earlier, and the measured temperature. On account of the DMPS time resolution, we have 1440 calculated values per attachment rate altogether. The aim is to plot attachment rate values as a function of ELPI current and show linear dependence. However, at first we introduce so-called theoretical ELPI current calculated from the DMPS data and compare it to measured ELPI current.

\subsection{Theoretical current compared to measured current}

The ELPI current response corresponding to each DMPS size distribution, also called theoretical ELPI current in this context, is calculated by means of the sensitivity function (11) and an equation

$I_{\text {theor }}=\int P n\left(d_{p}\right) e Q \cdot \mathcal{N}\left(d_{p}\right) \mathrm{d} d_{p}$.

In Fig. 4 theoretical ELPI current is plotted as a function of measured current for both the field data and the laboratory data. In the field the currents are directly proportional to each other with a correlation of 0.909 and in the laboratory the correlation is 0.989 . For comparison, Ntziachristos et al. (2007) calculated the correlations of the NSAM output and the SMPS based theoretical output. They found correlations of 0.94 and 0.64 for urban and fresh traffic aerosols, respectively. Our result confirms the method of calculating theoretical current from the DMPS data as reasonable. The most important result in the laboratory measurements was that the ELPI sensitivity function is still valid despite of the large variation in particle concentration and variation in GMD of one-modal distributions.
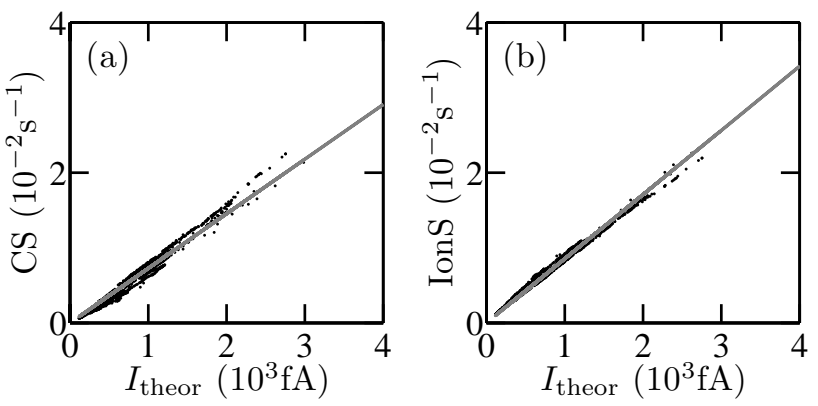

Fig. 5. The values of (a) condensation sink and (b) ion sink calculated from the DMPS size distributions as a function of theoretical ELPI current, which is also calculated from the DMPS data using the number sensitivity function.

In Fig. 4 the slope of the fitting is 0.885 in the field and 0.854 in the laboratory, which means there are constant factors between the output signals of the ELPI and the reference instruments, i.e. DMPS in the field and SMPS in the laboratory. Both the factors are smaller than unity, so the measured current is greater than theoretical. However, the difference between those two factors is very small, only $3.5 \%$, despite of the different reference instruments.

\subsection{Theoretical calibration}

By theoretical calibration we mean that the outdoor ELPI is calibrated to measure the attachment rates using only DMPS data and theoretical ELPI current. In Fig. 5 the attachment rates are plotted as a function of theoretical ELPI current for the field data. Fittings have been made into the set of points with the method of least squares. The fitted curves are straight lines without a constant term, so the only value describing the compatibility of the fit is the slope which we call the calibration factor $\Lambda$. Theoretical calibration factors are shown in Table 1 for condensation sink and in Table 2 for ion sink. The same calculation procedure was made for the laboratory data and corresponding calibration factors are seen in the tables.

\subsection{Calibration using measured ELPI current}

Instead of theoretical ELPI current, measured ELPI current can be used. There are both advantages and disadvantages in working with the measured current. For ELPI it is definitely more realistic and it takes into account all the losses and characteristics of the instrument affecting the output signal. On the other hand, if there, for some reason, is a difference between the total concentration of the sample measured by DMPS and ELPI, it will have a direct effect on the calibration factor. 
Table 1. Calibration factors $\Lambda$ for condensation sink with $95 \%$ confidence bounds, the correlation of the fitting and the root mean square error describing the final error of the measured attachment rate.

\begin{tabular}{lcccc}
\hline $\mathrm{CS}$ & $\Lambda\left(\mathrm{s}^{-1} \mathrm{fA}^{-1}\right)$ & corr $(-)$ & $\mathrm{rmse}\left(\mathrm{s}^{-1}\right)$ & $95 \%$ confidence interval $\left(\mathrm{s}^{-1} \mathrm{fA}^{-1}\right)$ \\
\hline Field, theoretical & $7.27 \mathrm{E}-06$ & 0.970 & $7.03 \mathrm{E}-04$ & {$[7.23-06 ; 7.31 \mathrm{E}-06]$} \\
Field, measured & $6.43 \mathrm{E}-06$ & 0.894 & $1.33 \mathrm{E}-03$ & {$[6.36 \mathrm{E}-06 ; 6.50 \mathrm{E}-06]$} \\
Lab, theoretical & $6.49 \mathrm{E}-06$ & 0.997 & $2.45 \mathrm{E}-02$ & {$[6.40 \mathrm{E}-06 ; 6.58 \mathrm{E}-06]$} \\
Lab, measured & $5.56 \mathrm{E}-06$ & 0.993 & $3.57 \mathrm{E}-02$ & {$[5.44 \mathrm{E}-06 ; 5.68 \mathrm{E}-06]$} \\
\hline
\end{tabular}

Table 2. Calibration factors $\Lambda$ for ion sink with $95 \%$ confidence bounds, the correlation of the fitting and the root mean square error describing the final error of the measured attachment rate.

\begin{tabular}{lcccc}
\hline IonS & $\Lambda\left(\mathrm{s}^{-1} \mathrm{fA}^{-1}\right)$ & corr $(-)$ & rmse $\left(\mathrm{s}^{-1}\right)$ & $95 \%$ confidence interval $\left(\mathrm{s}^{-1} \mathrm{fA}^{-1}\right)$ \\
\hline Field, theoretical & $8.55 \mathrm{E}-06$ & 0.989 & $4.36 \mathrm{E}-04$ & {$[8.52 \mathrm{E}-06 ; 8.57 \mathrm{E}-06]$} \\
Field, measured & $7.57 \mathrm{E}-06$ & 0.891 & $1.36 \mathrm{E}-03$ & {$[7.50 \mathrm{E}-06 ; 7.64 \mathrm{E}-06]$} \\
Lab, theoretical & $9.07 \mathrm{E}-06$ & 0.999 & $1.52 \mathrm{E}-02$ & {$[9.01 \mathrm{E}-06 ; 9.13 \mathrm{E}-06]$} \\
Lab, measured & $7.73 \mathrm{E}-06$ & 0.986 & $7.23 \mathrm{E}-02$ & {$[7.50 \mathrm{E}-06 ; 7.97 \mathrm{E}-06]$} \\
\hline
\end{tabular}
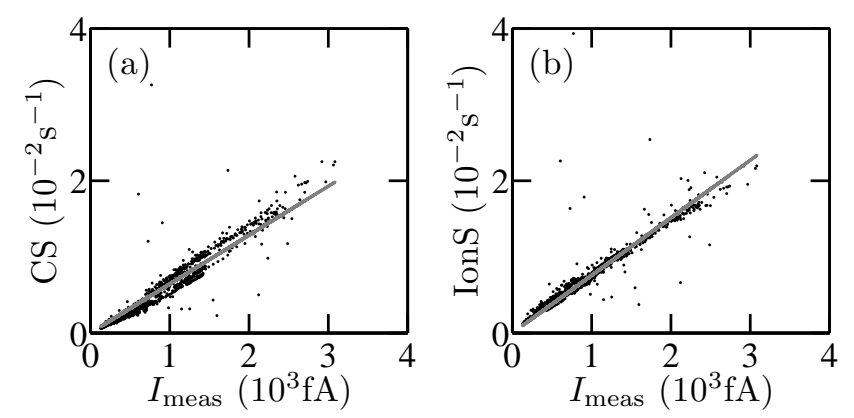

Fig. 6. The values of (a) condensation sink and (b) ion sink calculated from the DMPS size distributions as a function of measured ELPI current.

The attachment rates as a function of measured ELPI current are shown in Fig. 6 for the field data and the corresponding calibration factors, as well as the calibration factors for the laboratory data, in the Tables 1 and 2. Note that the deviation is more pronounced in this case than in the theoretical case and the values of the calibration factors are slightly different. In Fig. 6 there are also some uncertain data points, which can be caused by a failure in the sample or in the operation of one of the two instruments. These failures are though completely random and they have practically no effect on the calibration factor values.

\subsection{Comparison}

We have now values of theoretical and measured calibration factors, calculated for both the field data and the laboratory data. At first, it can be noticed that the laboratory values differ slightly from the calibration factors based on the field calibration, namely for condensation sink they are about $11 \%$ smaller and for ion sink about $6 \%$ greater. The reason is that in the laboratory data a majority of the distributions has a GMD of 50-70 nm, but in the field data the tendency of the particle size distributions is somewhat larger. Therefore, the difference between the calibration factors is very logical, if we look at the Fig. 2 and the response functions. However, our aim is to measure the attachment rates in the atmosphere so we use the calibration factors gained from the field data.

There is still two sets of calibration factors, some based on solely the DMPS data and the others based on the measured ELPI current. There is a constant factor between those two sets and it is the same as the earlier found factor between theoretical and measured ELPI current.

To show the relevance of the usage of the calibration factors in practice, we have plotted the values of condensation sink and ion sink as function of time in Fig. 7. Both the values calculated from DMPS and the values calculated from the ELPI current are shown. In this figure, we have used the calibration factors based on the measured ELPI current to make the values comparable. The agreement between the two methods is very good.

\section{Summary and conclusions}

We have shown that ELPI is an instrument able to measure condensation sink and ion sink of atmospheric aerosol particles. The characterization of particle formation and growth processes has recently been a key to understand indirect climate effects of the atmospheric aerosol. In this respect, need for a simple real-time measuring instrument of the surfacerelated quantities connected to these processes seems to be growing. 

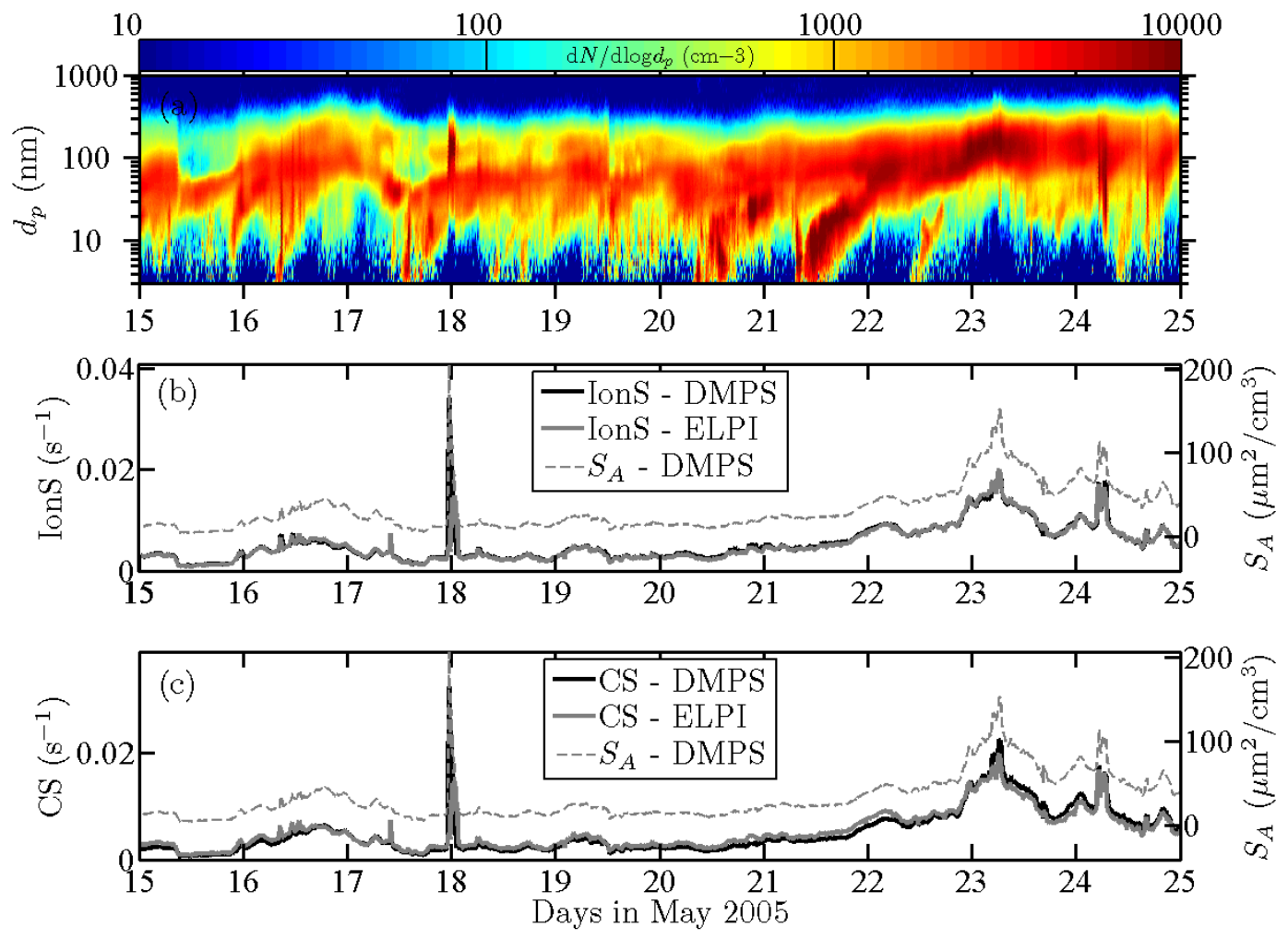

Fig. 7. The number size distributions (a), ion sink (b) and condensation sink (c) as a function of time. In panels (b) and (c) there are both quantities calculated from the DMPS size distributions and quantities calculated from the ELPI total current using the calibration factors based on the measured ELPI current. The surface area concentration calculated from the DMPS data is shown on secondary vertical axis in both the panels.

We made calibrations based on the DMPS and ELPI data measured in a boreal forest environment. There was a slight difference, about $10 \%$, between the theoretical calibration factors and the calibration factors based on the measured ELPI current. Could the difference between the size ranges of ELPI $(7 \mathrm{~nm}-6 \mu \mathrm{m})$ and DMPS $(3 \mathrm{~nm}-500 \mathrm{~nm})$ be the reason for this? In fact, it could be a part of the explanation, but it does not account for the whole difference because small particles inflict such a minimal current and there are very few particles in the size range $500 \mathrm{~nm}-6 \mu \mathrm{m}$. The relative difference between the measured current and the current corrected with the size range and the diffusion losses was checked to be under $4 \%$. An error in the sensitivity function of the outdoor ELPI may also be a cause for the difference. Another explanation is that there is an error in the total concentration of the sample measured by ELPI or DMPS caused for example by an error in the flow rate. With only one major flow, the ELPI is not very prone to errors in the total concentration. In this respect, DMPS may be more vulnerable. Therefore, we favour the theoretical calibration factors, which assume that ELPI operates theoretically correct, and the DMPS total concentration does not shift the result.
Finally, we establish the universal calibration factors: 7.27E-06 s-1 $\mathrm{fA}^{-1}$ for condensation sink and 8.55E-06 $\mathrm{s}^{-1} \mathrm{fA}^{-1}$ for ion sink. By multiplying the total current of the outdoor ELPI by these factors the values of the attachment rates can be measured. This is a very simple method and it brings all the advantages of ELPI to measurements of the attachment rates.

\section{References}

Adachi, M., Kousaka, Y., and Okuyama, K.: Unipolar and bipolar diffusion charging of ultrafine aerosol particles, J. Aerosol Sci., 16, 109-123, 1985.

Bukowiecki, N., Kittelson, D. B., Watts, W. F., Burtscher, H., Weingartner, E., and Baltensperger, U.: Real-time characterization of ultrafine and accumulation mode particles in ambient combustion aerosols, J. Aerosol Sci., 33, 1139-1154, 2002.

Dekati Ltd.: Dekati Ltd.: ELPI charging efficiencies, http://www. dekati.com/cms/files/File/PDF/ELPIChargingefficiencies2007. pdf, last access: January 2010, 2007.

Eiceman, G. A. and Karpas, Z.: Ion Mobility Spectrometry, CRC Press Taylor \& Francis, Boca Raton, 2. Edn., 2005.

Eisele, F. L. and Tanner, D. J.: Identification of ions in continental air, J. Geophys. Res., 95, 20539-20550, 1990. 
Fissan, H., Trampe, A., Neunman, S., Pui, D. Y. H., and Shin, W. G.: Rationale and principle of an instrument measuring lung deposition area, J. Nanopart. Res., 9, 53-59, 2006.

Fuchs, N. A.: On the stationary charge distribution on aerosol particles in a bipolar ionic atmosphere, Geofisca Purae Applicata, 56, 185-193, 1963.

Fuchs, N. A. and Sutugin, A. G.: High-dispersed aerosols, in: Current Aerosol Research, edited by: Hidy, G. M. and Brock, J., 1-60, Pergamon, Oxford, 1971.

Gäggeler, H. W., Baltensperger, U., and Emmenegger, M.: The epiphanometer, a new device for continuous aerosol monitoring, J. Aerosol Sci., 20, 557-564, 1989.

Hõrrak, U., Aalto, P. P., Salm, J., Komsaare, K., Tammet, H., Mäkelä, J. M., Laakso, L., and Kulmala, M.: Variation and balance of positive air ion concentrations in a boreal forest, Atmos. Chem. Phys., 8, 655-675, 2008,

http://www.atmos-chem-phys.net/8/655/2008/.

Hari, P. and Kulmala, M.: Station for Measuring EcosystemAtmosphere Relations (SMEAR II), Boreal Environ. Res., 10, 315322, 2005.

Haywood, J. M. and Shine, K. P.: The effect of anthropogenic sulfate and soot aerosol on the clear sky planetary radiation budget, Geophys. Res. Lett., 22, 603-606, 1995.

Hoppel, W. A. and Frick, G. M.: Ion-aerosol attachment coefficients and the steady-state charge distribution on aerosols in a bipolar ion environment, Aerosol Sci. Tech., 5, 1-21, 1986.

Keskinen, J., Lehtimäki, M., and Graeffe, G.: Radon decay product attachment rates in dwellings, J. Aerosol Sci., 22, 765-771, 1991.

Keskinen, J., Pietarinen, K., and Lehtimäki, M.: Electrical low pressure impactor, J. Aerosol Sci., 23, 353-360, 1992.

Kulmala, M. and Kerminen, V.-M.: On the formation and growth of atmospheric nanoparticles, Atmos. Res., 90, 132-150, 2008.

Kulmala, M., Dal Maso, M., Mäkela, J. M., Pirjola, L., Väkevä, M., Aalto, P., Miikkulainen, P., Hämeri, K., and O'Dowd, C. D.: On the formation, growth and composition of nucleation mode particles, Tellus B, 53, 479-490, 2001.

Kulmala, M., Vehkamäki, H., Petäjä, T., Dal Maso, M., Lauri, A., Kerminen, V.-M., Birmili, W., and McMurry, P. H.: Formation and growth rates of ultrafine atmospheric particles: A review of observations, J. Aerosol Sci., 35, 143-176, 2004.

Lohmann, U. and Feichter, J.: Global indirect aerosol effects: a review, Atmos. Chem. Phys., 5, 715-737, 2005, http://www.atmos-chem-phys.net/5/715/2005/.

Mäkelä, J. M., Aalto, P., Jokinen, V., Pohja, T., Nissinen, A., Palmroth, S., Markkanen, T., Seitsonen, K., Lihavainen, H., and Kulmala, M.: Observations of ultrafine aerosol particle formation and growth in boreal forest, Geophys. Res. Lett., 24, 1219-1222, 1997.
Marjamäki, M., Keskinen, J., Chen, D. R., and Pui, D. Y. H.: Performance evaluation of the electrical low-pressure impactor (ELPI), J. Aerosol Sci., 31, 249-261, 2000.

Ntziachristos, L., Giechaskiel, B., Ristimäki, J., and Keskinen, J.: Use of a corona charger for the characterisation of automotive exhaust aerosol, J. Aerosol Sci., 35, 943-963, 2004.

Ntziachristos, L., Polidori, A., Phuleria, H., Geller, M. D., and Sioutas, C.: Application of a diffusion charger for the measurement of particle surface area concentration in different environments, Aerosol Sci. Tech., 41, 571-580, 2007.

Pandis, S. N., Baltensperger, U., Wolfenbarger, J. K., and Seinfeld, J. H.: Inversion of aerosol data from the epiphaniometer, J. Aerosol Sci., 22, 417-428, 1991.

Pirjola, L., Kulmala, M., Wilck, M., Bischoff, A., Stratmann, F., and Otto, E.: Formation of sulphuric acid aerosols and cloud condensation nuclei: an expression for significant nucleation and model comparison, J. Aerosol Sci., 30, 1079-1094, 1999.

Poling, B. E., Prausnitz, J. M., and O'Connel, J. P.: The Properties of Gases and Liquids, McGraw-Hill, 2000.

Porstendörfer, J. and Mercer, T. T.: Adsorption propability of atoms and ions on particle surfaces in submicrometer size range, J. Aerosol Sci., 9, 469-474, 1978.

Riipinen, I., Sihto, S.-L., Kulmala, M., Arnold, F., Dal Maso, M., Birmili, W., Saarnio, K., Teinilä, K., Kerminen, V.-M., Laaksonen, A., and Lehtinen, K. E. J.: Connections between atmospheric sulphuric acid and new particle formation during QUEST IIIIV campaigns in Heidelberg and Hyytiälä, Atmos. Chem. Phys., 7, 1899-1914, 2007,

http://www.atmos-chem-phys.net/7/1899/2007/.

Shin, W. G., Pui, D. Y. H., Fissan, H., Neumann, S., and Trampe, A.: Calibration and numerical simulation of Nanoparticle Surface Area Monitor (TSI Model 3550 NSAM), J. Nanopart. Res., 9, 61-69, 2007.

Siegmann, K. and Siegmann, H. C.: Fast and reliable "in situ" evaluation of particles and their surfaces with special reference to diesel exhaust, Tech. Rep. 2000-01-1995, SAE, 2000.

Vohra, K. G., Subba Ramu, M. C., and Vasudevan, K. N.: Nucleation of Water Cluster Ions, reports Bhabba Atomic Research Centre, Bombay, 1969.

Wang, S. C. and Flagan, R. C.: Scanning electrical mobility spectrometer, Aerosol Sci. Tech., 13, 230-240, 1990.

Woo, K.-S., Chen, D.-R., Pui, D. Y. H., and Wilson, W. E.: Use of continuous measurements of integral aerosol parameters to estimate particle surface area, Aerosol Sci. Tech., 34, 57-65, 2001. 